\title{
Echocardiographic criteria for Ebstein's anomaly of tricuspid valve
}

\author{
W J GUSSENHOVEN, S E C SPITAELS, N BOM, A E BECKER
}

\begin{abstract}
From the Interuniversity Cardiology Institute, Thoraxcenter, Rotterdam; the Department of Paediatric Cardiology, Sophia Kinderziekenhuis, Rotterdam; the Thoraxcenter, Erasmus University, Rotterdam; and the Department of Pathology, Wilhelmina Gasthuis, University of Amsterdam, Amsterdam, The Netherlands
\end{abstract}

SUMMARY The diagnostic echocardiographic features of Ebstein's malformation of the tricuspid valve have been evaluated in two groups of patients, using $M$-mode and two-dimensional techniques. The first group consisted of nine patients in whom previous $M$-mode studies had suggested the existence of Ebstein's anomaly. The second group consisted of 20 patients, all suffering from right heart overload, in whom Ebstein's malformation was excluded at open heart surgery. The M-mode studies disclosed that none of the criteria currently employed could be considered diagnostic. A delay in tricuspid valve closure of more than $65 \mathrm{~ms}$, considered the most reliable indicator, was also present in eight of 20 'controls'. The characteristic anatomical feature, that is distal displacement of the septal tricuspid leaflet, was never identified with certainty using M-mode echograms, in contrast to twodimensional echograms which showed a high degree of accuracy. Two-dimensional techniques disclosed an abnormal insertion in six of nine patients in the first group, while a normal insertion was positively identified in 13 of 14 patients with right heart overload. In two of the nine patients in whom Ebstein's anomaly was suggested by $M$-mode criteria, a normal septal origin was identified and all further attempts to substantiate this diagnosis failed. In one patient from the first group, the two-dimensional study was inconclusive regarding positive identification of the septal origin. Open heart surgery showed a normal origin of the septal leaflet, though the valve was plastered to the septal surface by short chordae. Only once among 14 'controls' was the septal attachment inconclusively identified with the two-dimensional echograms. Surgery, however, excluded the presence of Ebstein's anomaly in this patient. Twodimensional echocardiography, aiming at visualising the septal origin of the tricuspid valve, thus seems to be useful in establishing a diagnosis of Ebstein's malformation of the tricuspid valve.

The clinical diagnosis of Ebstein's anomaly of the tricuspid valve is notoriously difficult, both with invasive and non-invasive investigations. The problem relates to the fact that Ebstein's anomaly, though an entity in itself, constitutes an anatomical spectrum with regard to the extent and degree of the valvar abnormality. ${ }^{1-3}$ The anomaly is characterised by distal displacement of the septal attachment of the valve, a feature which may extend on to the inferior part of the tricuspid valve, and is almost always combined with various degrees of valve dysplasia.

The echocardiographic diagnosis of Ebstein's anomaly, using $\mathrm{M}$-mode techniques, depends on the identification of an increase in motion amplitude of the anterior tricuspid valve leaflet, an increase in

Received for publication 20 August 1979 the dimensions of the right ventricular cavity, the presence of paradoxical septal motion, the ability to record the tricuspid valve more to the left of the sternum than usual, and a delay in closure of the tricuspid valve as compared with that of the mitral valve. ${ }^{4-10}$ However, it is not certain how reliable these indices are as diagnostic criteria. This is an important question since the truly diagnostic criterion, that is the distal displacement of the attachment of the septal leaflet, is not readily obtained with the M-mode echogram. As recently stated, two-dimensional methods may prove to be of value in this respect, since this technique enables the actual identification of the abnormal origin of the valve. ${ }^{811}$

It is for this reason that we have employed a twodimensional echocardiographic technique to restudy a group of nine patients in whom the diagnosis 
of Ebstein's anomaly of the tricuspid valve had previously been suggested from the currently accepted $\mathrm{M}$-mode echographic criteria. In order to assess these criteria another 20 patients, known to have right ventricular volume overload resulting from a variety of causes other than Ebstein's anomaly, were also studied.

\section{Subjects and methods}

The material for this study consisted of two groups of patients. The first group was composed of nine patients (six male and three female) ranging in age from 16 to 56 years (average 33 years), all of whom were considered to have Ebstein's anomaly of the tricuspid valve. This presumptive diagnosis had been based on identification of at least two of the following five $M$-mode criteria ${ }^{4-10}$ : an amplitude of the anterior tricuspid valve leaflet motion of $20 \mathrm{~mm}$ or more; a right ventricular dimension of $30 \mathrm{~mm}$ or more; paradoxical septal motion defined as movement parallel to the motion of the echo from the posterior heart wall during ventricular systole ${ }^{12}$; lateral displacement of the tricuspid valve, defined as the situation in which the tricuspid valve motion can be recorded more to the left of the sternum than usual, taking the left parasternal line as the borderline; and a delay in closure of the tricuspid valve of $65 \mathrm{~ms}$ or more, as compared with that of the mitral valve.

In each of these nine patients invasive studies were done in an attempt to verify the presumptive diagnosis.

The second group comprised 20 patients (eight men and 12 women) ranging in age from 21 to 66 years (average 38). They were selected because cardiac catheterisation had shown right heart overload in each. In 13, this was the result of an isolated atrial septal defect of the fossa ovalis type, and in two of an atrial septal defect complicated by partial anomalous pulmonary venous connection; another four had tricuspid regurgitation in the presence of longstanding mitral regurgitation and/or stenosis. One patient had an atrial septal defect in the presence of pulmonary stenosis. In each patient the possibility of Ebstein's anomaly had been ruled out at open heart surgery.

The same echographic studies were performed in both groups. The $M$-mode studies were performed with the echocardiovisor 01, and recorded on a line scan recorder (Honeywell visicorder 1856) using light-sensitive paper (Kodak type 1895). The tracings were recorded at paper speeds of both 2.5 and $5 \mathrm{~cm} / \mathrm{s}$, in order that precise timing in the measurements might be made. The two-dimensional images were made with a dynamically focused multiscan system. ${ }^{13}$

\section{ANATOMY}

In order to appreciate the diagnostic possibilities of both M-mode and two-dimensional echocardiograms for Ebstein's anomaly, it is necessary to recall the basic anatomical derangements in this condition.

The disease is characterised by two main features. ${ }^{1-3}$ First, part of the basal attachment of the tricuspid valve is displaced distally, thereby creating a so-called atrialised part of the right ventricle (Fig. 1). Distal displacement affects the septal leaflet but this varies in extent with the inferior leaflet. The anterior leaflet, on the other hand, always originates from the annulus fibrosus. The second anatomical feature of Ebstein's anomaly is dysplasia of the valve, often characterised by a sail-like deformity of the 'non-displaced' anterior leaflet. However, as with distal displacement, the extent and degree of valve dysplasia may vary considerably from one patient to the other. ${ }^{2}{ }^{3}$ In some instances the 'sail-like' anterior leaflet may be free floating, while in others the leaflet is 'plastered' to the right ventricular free wall. In the latter circumstances the valve leaflet can be much restricted in its mobility. In rare circumstances, moreover, the septal inferior and anterior leaflets may become continuous, thus creating a severe inlet obstruction to the right ventricular outlet; a situation that clinically may mimic 'classical' tricuspid atresia.

From the point of view of echographic identification of Ebstein's anomaly, distal displacement of the septal origin of the valve seems by far the best criterion since dysplasia in itself is not readily distinctive (Fig. 1).

\section{Results}

The echographic data obtained from the nine patients initially diagnosed as having an Ebstein's anomaly of the tricuspid valve are shown in the Table. The $M$-mode studies revealed that the motion amplitude of the anterior tricuspid valve leaflet was increased in all, whereas in eight there was an abnormal increase of the right ventricular dimension. Lateral 'displacement' of the tricuspid valve was obvious in seven patients, while this feature was inconclusive in two. Delay in closure of the tricuspid valve of more than 65 milliseconds was present in eight and paradoxical septal motion in six patients.

Deliberate attempts to identify the septal attachment of the tricuspid valve using the M-modemethod were unsuccessful in all nine patients. In only one (case 7) was the suggestion of a low insertion raised, since the septal tricuspid valve leaflet was recorded only when the ultrasound beam 

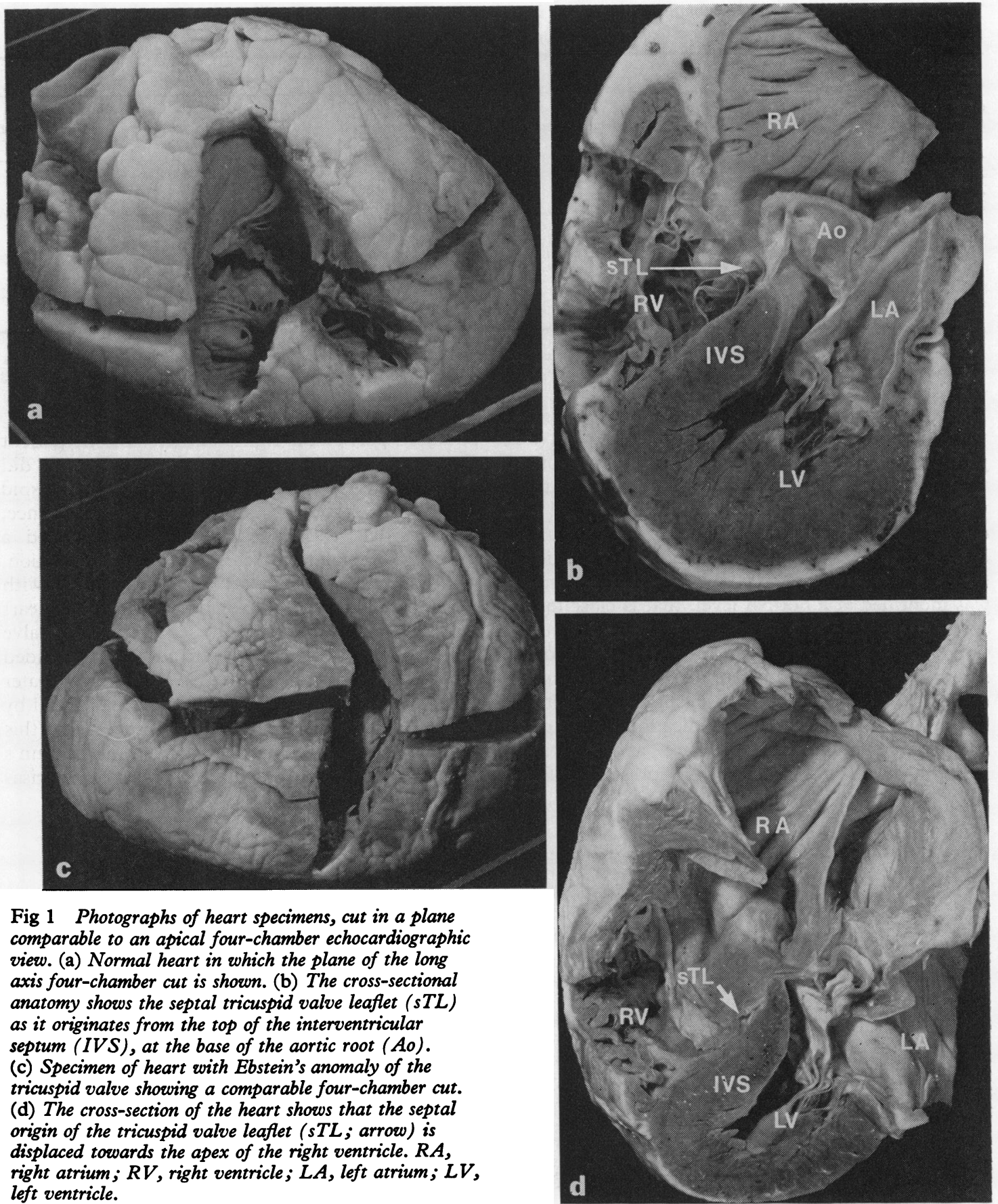

Fig 1 Photographs of heart specimens, cut in a plane comparable to an apical four-chamber echocardiographic view. (a) Normal heart in which the plane of the long axis four-chamber cut is shown. (b) The cross-sectional anatomy shows the septal tricuspid valve leaflet (sTL) as it originates from the top of the interventricular septum (IVS), at the base of the aortic root (Ao). (c) Specimen of heart with Ebstein's anomaly of the tricuspid valve showing a comparable four-chamber cut. (d) The cross-section of the heart shows that the septal origin of the tricuspid valve leaflet (sTL; arrow) is displaced towards the apex of the right ventricle. $R A$, right atrium; $R V$, right ventricle; $L A$, left atrium; $L V$, left ventricle.

swept close to the right ventricular apex (Fig. 2). In some instances an accumulation of echoes was observed at the right ventricular site of the interventricular septum, but these echoes were never positively identified as representing a displaced valve leaflet (Fig. 3a).

Two-dimensional echograms, on the other hand, visualised the septal attachment of the tricuspid 
Table M-mode and two-dimensional data obtained in nine patients suspected of having Ebstein's anomaly of tricuspid valve according to current $M$-mode criteria (see text)

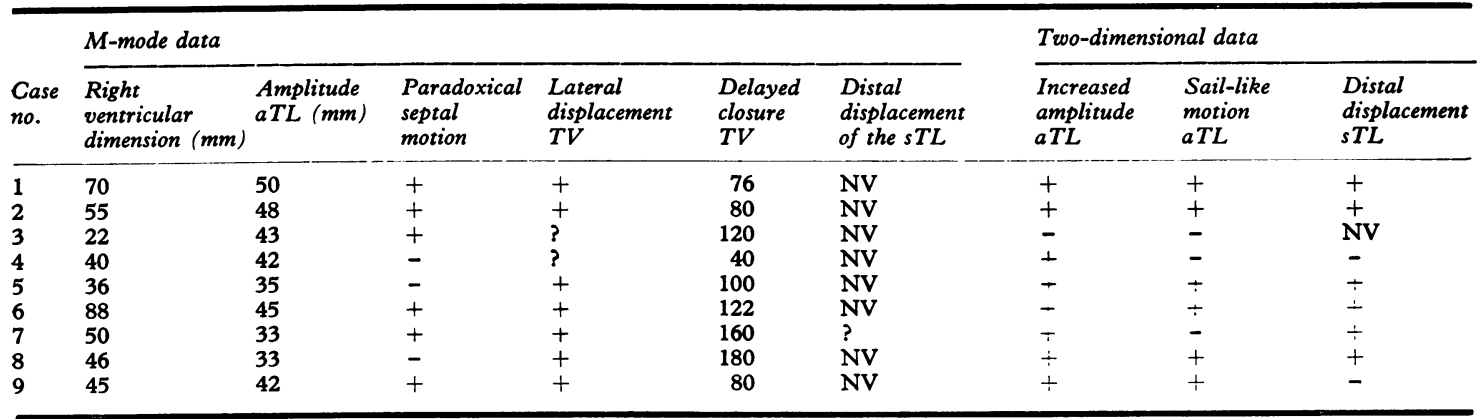

Abbreviations: aTL, anterior tricuspid valve leaflet; TV, tricuspid valve; sTL, septal tricuspid valve leaflet; + , present; - , absent; ?, questionable; NV, not visualised.

valve in eight patients and distal displacement was positively identified in six. The 'ideal' position of the transducer, enabling positive identification, varied from one individual to the other and encompassed classical long axis, cross-sectional, and apical views (Fig. $3 \mathrm{~b}$ and $\mathrm{c}$, and $4 \mathrm{a}$ ). In two patients (Table; cases 4 and 9) the septal attachment was identified at a normal level, that is close to the aortic root (compare Fig. $4 a$ and $b$ ), at the junctional level between mitral valve, interventricular septum, and interatrial septum; catheter studies confirmed the presence of tricuspid regurgitation, but in neither was there any indication of Ebstein's anomaly. Simultaneous pressure and electrical recordings did not disclose the presence of an atrialised part of the right ventricle. In one patient (Table; case 3) the two-dimensional echogram did not visualise the septal attachment of the tricuspid valve. This patient is of particular significance, since cardiac catheterisation studies disclosed a large atrial septal defect with tricuspid regurgitation, while Ebstein's anomaly could not be excluded with certainty from the angiograms. At open heart surgery it was noticed that the septal tricuspid valve leaflet took a normal origin from the right-sided annulus fibrosus, but the leaflet was for its greater part plastered to the right ventricular septal wall by short chordae. These observations suggest that this anomaly may fit within the category of Ebstein's anomaly of the tricuspid valve. Cardiac catheterisa-

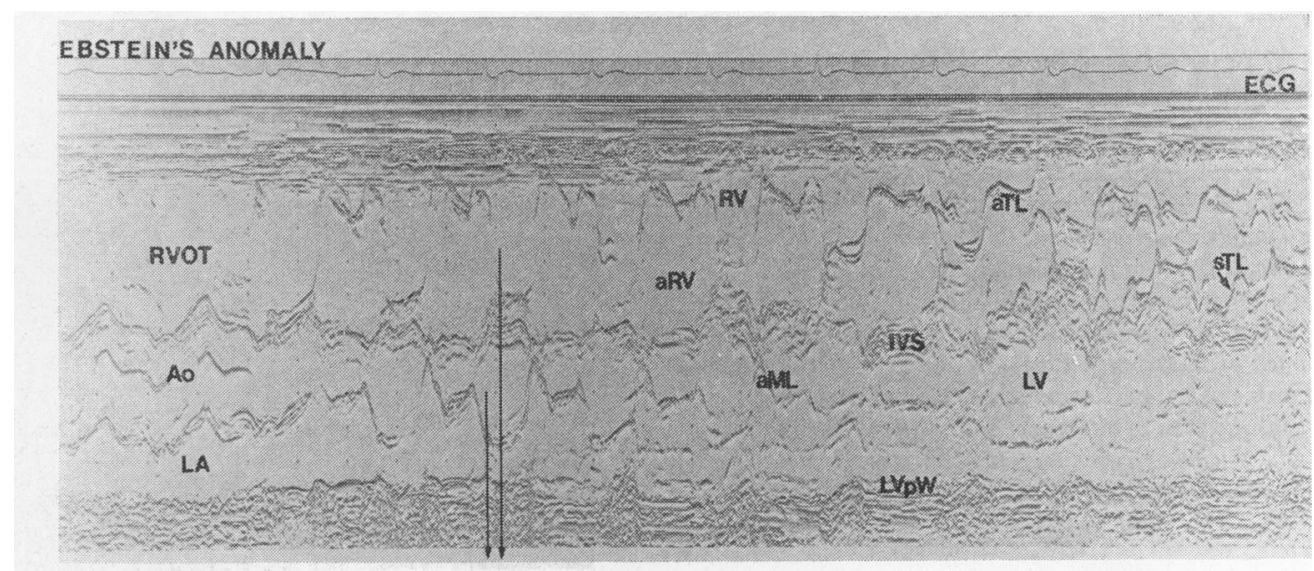

Fig. 2 A male patient, 23 years of age (Table; case 7) with proven Ebstein's anomaly. In the M-mode recording the septal tricuspid valve leaflet (sTL; arrow) appeared only when the ultrasound beam swept close to the right ventricular apex. The long and short arrows indicate the time of closure of the tricuspid and mitral valves, respectively. Note the delayed closure of the former. RVOT, right ventricular outflow tract; Ao, aorta; LA, left atrium; aML, anterior mitral valve leaflet; LV, left ventricle; IVS, interventricular septum; $R V$, right ventricle; aRV, atrialised right ventricle; aTL, anterior tricuspid leaflet; $s T L$, septal tricuspid leaflet; LVpW, left ventricular posterior wall. 


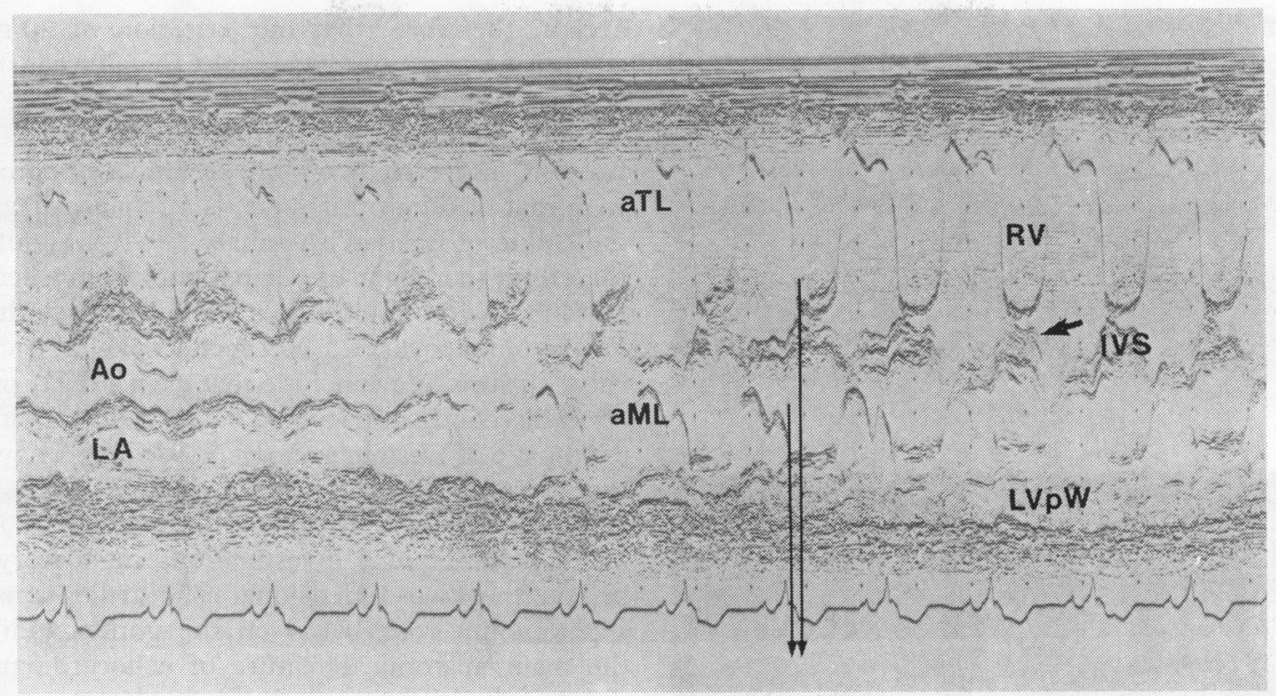

(a)

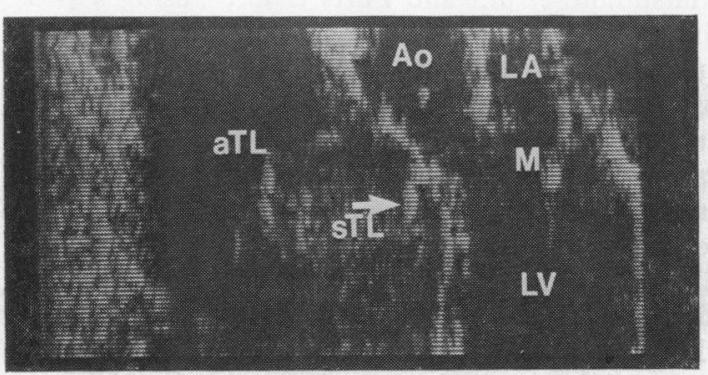

(b)

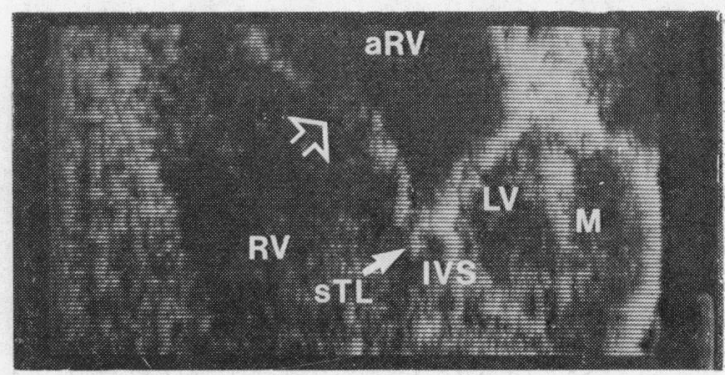

(c)

Fig. 3 A female patient, 22 years of age (Table; case 2) with proven Ebstein's anomaly of the tricuspid valve. (a) M-mode tracing which discloses an increase in the right ventricular dimension and the motion amplitude of the anterior tricuspid leaflet, delayed closure of the tricuspid valve of $80 \mathrm{~ms}$, and paradoxical movement of the interventricular septum. The arrow points to multiple echoes at the right ventricular site of the interventricular septum. Abbreviations as in Fig. 2. (b) and (c) Two-dimensional long axis and cross-sectional views, respectively, of the same patient. The septal tricuspid leaflet (sTL; arrow) takes an abnormal 'low' insertion from the interventricular septum (IVS). The atrialised part of the right ventricle $(a R V)$ is well seen in (c). Note the large anterior tricuspid leaflet in both views ( $a T L$ in $3 \mathrm{~b}$ and open arrow in $3 \mathrm{c}$ ). Ao, aorta; $L A$, left atrium; $L V$, left ventricle; $M$, mitral valve.

tion in the remaining six patients, that is those with positive two-dimensional echographic identification of Ebstein's disease, were all in accord with this diagnosis.

In the second group of patients, that is those with right ventricular overload, the $M$-mode studies also showed a high percentage of positivity for the 'Ebstein's' criteria (vide supra). The right ventricular dimensions were increased in all and in eight the amplitude of the anterior tricuspid valve leaflet motion was also increased. Paradoxical septal motion was present in 16 , and lateral displacement of the tricuspid valve was identified in eight. Delayed closure of the tricuspid valve, as defined previously, was present in eight patients and ranged from 70 to 260 milliseconds. Distal displacement was not recognised in any of these 20 patients.

Two-dimensional echocardiograms were obtained from 14 of these 20 patients. In 13, a normal septal origin was recorded (Fig. 4b). On only one occasion was the septal origin not visualised and that was in a patient suffering from an atrial septal defect of the fossa ovalis type with mild pulmonary stenosis. 


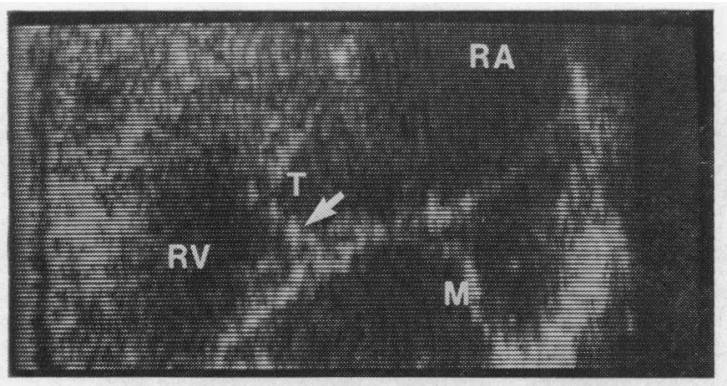

(a)

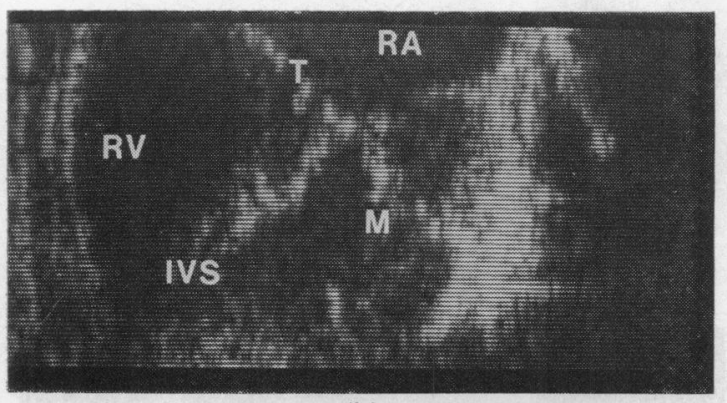

(b)

Fig. 4 Two-dimensional echocardiograms showing similar apical views in a patient with Ebstein's anomaly (Fig. 4a) and a patient with right heart overload resulting from an atrial septal defect (Fig. 4b). In this particular plane of sectioning the mitral $(M)$ and tricuspid $(T)$ valves normally should meet at the site of junction between the interventricular septum (IVS) and the interatrial septum (Fig. 4b). Note the distal origin (arrow) of the septal tricuspid valve in Ebstein's anomaly (Fig. 4a).

$R A$, right atrium; $R V$, right ventricle.

\section{Discussion}

The present studies unequivocally show that the current $\mathrm{M}$-mode criteria for the diagnosis of Ebstein's anomaly of the tricuspid valve are in themselves non-diagnostic, most of the indices appearing related to secondary haemodynamic effects rather than an anomaly of the valve. Conditions characterised by volume overload of the right ventricle may lead to an increase in right ventricular dimension and paradoxical septal movements. Moreover, the anterior leaflet of the tricuspid valve under these circumstances is easily picked up by the transducer, a feature which may be recorded as an increased amplitude of leaflet motion. In itself the amplitude recorded is highly dependent on the position of the transducer. In fact, this is one of the major reasons why a precise delineation of the range of normality has not yet been established. We accept, therefore, that our criterion of $20 \mathrm{~mm}$ is arbitrary, but in our experience this value constitutes an average of 'normality' for adult patients. Most authors agree that delay in closure of the tricuspid valve of more than 65 milliseconds, as compared with that of the mitral valve, is a reliable diagnostic indication of Ebstein's anomaly. ${ }^{4-10}$ It is significant, therefore, that eight of our patients from a series of $20(40 \%)$ without Ebstein's anomaly but with right heart volume overload had such a delay in tricuspid valve closure. We conclude that even a delay of over 65 milliseconds in tricuspid valve closure cannot be diagnostic of Ebstein's anomaly. We agree, however, that a combination of these $\mathrm{M}$-mode data should alert one to the possibility of Ebstein's anomaly, making subsequent investigations mandatory. We believe that two-dimensional echocardiograms play a paramount role, based on the understanding of the main anatomical feature of echocardiographic significance, that is the distal displacement of the septal origin of the tricuspid valve. Recently, Matsumoto et al. ${ }^{8}$ and Ports et al., ${ }^{11}$ using a twodimensional method, have diagnosed Ebstein's anomaly from this particular feature. Our results further indicate that positive identification of an abnormally low insertion of the septal tricuspid valve leaflet is indeed a reliable indicator of Ebstein's anomaly. Among our nine patients in whom the combination of $\mathrm{M}$-mode data had suggested Ebstein's anomaly, there were six in whom the twodimensional method actually showed distal displacement. In two patients, however, a normal septal origin of the valve was recorded and it is of interest that extensive intracardiac catheter studies failed to substantiate further this diagnosis. In one patient the septal attachment was not visualised with the two-dimensional technique. This inconclusive finding is significant since open heart surgery in this patient disclosed an abnormal septal valve leaflet. The valve took its normal origin, but the leaflet was for its greater part plastered to the septal surface. One could argue that this is not Ebstein's anomaly of the tricuspid valve, but, on the other hand, this observation also serves to indicate that even with two-dimensional techniques some extreme variants of Ebstein's anomaly will not be recognised. For instance, this might occur where extreme distal displacement of the septal and inferior leaflets is associated with a membrane-like continuum into the anterior leaflet, thereby creating a so-called imperforate Ebstein anomaly. Nevertheless, the two-dimensional method seems accurate as further substantiated by the findings in our group of patients without Ebstein's anomaly. While the M-mode data in some of them suggested the possibility of Ebstein's anomaly, the two-dimensional echograms 
showed a normal septal origin in almost all. In only one patient was the septal origin not visualised -a patient suffering from an atrial septal defect and mild pulmonary stenosis.

To obtain the best results, the transducer should be placed in a transverse position close to the apex of the heart and perpendicular to the plane of the long axis view. The operator should direct the plane of the image slightly upwards, so that the aortic root region is clearly visualised. The plane of 'sectioning' thus fluctuates between the standard cross-sectional and apical four-chamber views. Abnormalities in the septal attachment of the tricuspid leaflet may thus be identified and one might expect even a small rim of dysplastic and displaced valve tissue to be detected. We, therefore, believe that the two-dimensional echocardiogram is valuable in patients suspected of having Ebstein's anomaly of the tricuspid valve.

\section{References}

${ }^{1}$ Ebstein $W(1866)$. Ueber einen sehr seltenen Fall von Insufficienz der Valvula tricuspidalis, bedingt durcheine angeborene hochgradige Missbildung derselben. Arch Anat Physiol 1866; 33: 238-54.

'Pechstein J. Beitrag zur Ebsteinschen Anomalie der Valvula tricuspidalis. Arch Kreislaufforsch 1957; 26: 282-337.

${ }^{3}$ Becker AE, Becker MJ, Edwards JE. Pathologic spectrum of dysplasia of the tricuspid valve. Features in common with Ebstein's malformation. Arch Pathol 1971; 91: 167-78.

${ }^{4}$ Lundström NR, Edler I. Ultrasoundcardiography in infants and children. Acta Paediatr Scand 1971; 60: 117-28.

${ }^{5}$ Lundström NR. Echocardiography in the diagnosis of Ebstein's anomaly of the tricuspid valve. Circulation 1973; 47: 597-605.

'Tajik AJ, Gau GT, Giuliani ER, Ritter DG, Schattenberg TT. Echocardiogram in Ebstein's anomaly with Wolff-Parkinson-White pre-excitation syndrome, type B. Circulation 1973; 47: 813-8.

${ }^{2}$ Farooki ZQ, Henry JG, Green EW. Echocardiographic spectrum of Ebstein's anomaly of the tricuspid valve. Circulation 1976; 53: 63-8.

${ }^{8}$ Matsumoto M, Matsuo H, Nagata S, et al. Visualization of Ebstein's anomaly of the tricuspid valve by twodimensional and standard echocardiography. Circulation 1976; 53: 69-79.

${ }^{\circ}$ Milner S, Meyer RA, Venables AW, Korfhagen J, Kaplan S. Mitral and tricuspid valve closure in congenital heart disease. Circulation 1976; 53: 513-8. ${ }^{10}$ Lundström NR. The tricuspid valve. In: Lundström NR, ed. Echocardiography in congenital heart disease. Amsterdam: Elsevier/North Holland, 1978: 117-22.

${ }^{11}$ Ports TA, Silverman NH, Schiller NB. Two-dimensional echocardiographic assessment of Ebstein's anomaly. Circulation 1978; 58: 336-43.

${ }^{12}$ Diamond MA, Dillon JC, Haine CL, Chang S, Feigenbaum $\mathrm{H}$. Echocardiographic features of atrial septal defect. Circulation 1971; 43: 129-35.

${ }^{13}$ Ligtvoet CM, Ridder J, Lancée CT. A dynamically focused multiscan system. In: Bom N, ed. Echocardiology with Doppler applications and real time imaging. The Hague: Martinus Nijhoff, 1977: 313-23.

Requests for reprints to Dr W J Gussenhoven, Experimental Echo-laboratory, PO Box 1738, 3000 DR Rotterdam, The Netherlands. 